\title{
PRENATAL DIAGNOSIS OF CONGENITAL HEART DISEASE AFFECTS PREOPERATIVE ACIDOSIS IN THE NEWBORN PATIENT
}

Paul M. Verheijen, MD $^{\mathrm{a}}$

Lukas A. Lisowski, MD ${ }^{\text {a }}$

Phillip Stoutenbeek, MD

J.François Hitchcock, MD

Joel I. Brenner, MD

Joshua A. Copel, MD

Charles S. Kleinman, $\mathrm{MD}^{\mathrm{c}}$

Erik J. Meijboom, MD

Ger B. W. E. Bennink, MD
Objectives: Congenital heart disease is the leading cause of death in the first year after birth. Prenatal diagnosis of the disease can optimize the preoperative condition of the patient and may help in the prevention of acidosis. In this retrospective study we compared the occurrence of metabolic acidosis in patients with and without prenatal diagnosis of a congenital heart disease.

Methods: Data of 408 patients who needed an operation for congenital heart disease within 31 days of life were analyzed retrospectively. Arterial blood gases at fixed time intervals and worst blood gas of 81 patients with and 327 patients without a prenatal diagnosis were compared, categorizing the patients on ductus dependency, anticipated univentricular or biventricular repair, and left-sided, right-sided, or no heart obstruction.

Results: In the overall group significant differences in lowest $\mathrm{pH}$, lowest base excess, and highest lactate level were found, with metabolic acidosis more common among the patients with a postnatal diagnosis. In the group of patients with ductus-dependent congenital heart disease, the difference between patients receiving a prenatal and those receiving a postnatal diagnosis was more significant than in the group with non-ductus-dependent lesions. Analyzing patients with right-sided, left-sided, and no obstruction separately, significant differences were found in the group with left-sided heart obstruction for lowest $\mathrm{pH}$ and base excess and in the group with rightsided heart obstruction for lowest base excess.

Conclusions: Prenatal diagnosis of congenital heart disease minimizes metabolic acidosis in patients with congenital heart disease and may be associated with improved long-term outcome and prevention of cerebral damage among this fragile group of patients, although no significant effect on direct surgical outcome was encountered. (J Thorac Cardiovasc Surg 2001;121:798-803)
Congenital heart disease remains the most important cause of death in the first year after birth. ${ }^{1}$ Mortality occurs mainly in patients with severe forms

From the Departments of Obstetrics, Pediatric Cardiology, and Thoracic Surgery, UMC, ${ }^{\text {a }}$ Utrecht, The Netherlands; the Department of Pediatric Cardiology, University of Maryland

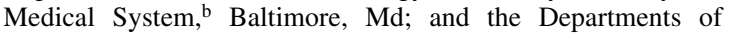
Obstetrics and Gynecology, and Pediatric Cardiology, Yale-New Haven Hospital, New Haven, Conn. ${ }^{\circ}$

This study was supported by a grant from the VSB Bank Foundation, the Netherlands Heart Foundation, and the SchootemeijerNiemans Foundation funded by the Prins Bernhard Foundation in The Netherlands.

Copyright (c) 2001 by The American Association for Thoracic Surgery

$0022-5223 / 2001 \$ 35.00+0 \quad \mathbf{1 2 / 1 / 1 1 2 8 2 5}$

doi: $10.1067 / \mathrm{mtc} .2001 .112825$ of congenital heart disease requiring immediate surgical intervention. Secondary to the improvement of surgical techniques over the last years, mortality has decreased dramatically, but important neurologic sequelae have been noted that may affect the quality of survival. ${ }^{2-4}$ Perfection of operative techniques has resulted in only minimal operative mortality and morbidity compared with the preoperative risk factors, as described by Soongswang and colleagues. ${ }^{5}$ Achieving a further decrease in mortality and morbidity will predominantly require improved preoperative stabilization of the patient. ${ }^{5,6}$ We hypothesize that the prenatal diagnosis of congenital heart disease facilitates the initiation of therapeutic intervention immediately after birth, including planned delivery at a cardiac center and immediate postnatal stabilization, which 
may include the initiation of prostaglandin therapy ${ }^{7}$ and intubation and ventilation if required. These measures may prevent neonatal hypoxemia, hypoperfusion, and acidosis. A salutary effect of prenatal cardiac diagnosis on neonatal survival has been proven for transposition of the great arteries by Bonnet and colleagues. ${ }^{8}$ This is the only article in the literature thus far that has the statistical power to show this effect. Some studies suggest improved outcomes in some subgroups of patients with prenatally diagnosed congenital heart disease. ${ }^{9-12}$ A significant effect on the overall group of patients with structural heart disease has not been shown. The purpose of this study was to evaluate retrospectively the effect of prenatal diagnosis on the newborn with congenital heart disease, comparing the incidence of metabolic acidosis in prenatally and postnatally diagnosed groups of patients with similar diagnoses.

\section{Patients and methods}

This retrospective study included patients diagnosed with congenital heart disease between January 1, 1991, and July 30, 1998, originating from 3 institutions: the University Medical Center, Utrecht, The Netherlands; Yale-New Haven Children's Hospital; and University of Maryland Medical System in Baltimore. All patients who required operations for structural heart disease in the first 31 days of life or died before the operation could take place were included. Excluded were patients with severe, life-threatening extracardiac or chromosomal anomalies.

Two different groups of patients with structural heart disease were compared, one in which the diagnosis was made prenatally and the other in which the cardiac anomaly was discovered after birth. Both groups received similar care at the same institutions.

The patients having a prenatal diagnosis were delivered within the University Hospitals, where indicated prostaglandin was started immediately and infants were intubated and ventilated if needed. The other patients were treated after congenital heart disease was suspected.

Outcome variables. Medical records were reviewed for age at diagnosis, mode of delivery, gestational age at delivery, Apgar scores, prostaglandin administration, and laboratory values, including arterial $\mathrm{pH}$, base excess $(\mathrm{BE}), \mathrm{PCO}_{2}, \mathrm{Po}_{2}$, and, if measured, lactate values. Arterial blood gases were those reported at 1 and 4 to 6 hours postpartum and worst blood gas, regardless of postnatal age in hours. These data were used to compare not only the 2 different groups described above but also to compare several sets of subgroups, including patients with and without ductus-dependent lesions, patients with a future possibility of biventricular repair, and those with an anticipated single ventricular repair. The outcomes in patients with left ventricular outflow tract obstruction, right ventricular outflow tract obstruction, and without any obstruction were compared separately.
Statistical analysis. Data were analyzed by using SPSS software (SPSS, Inc, Chicago, Ill). The Student $t$ test was used for comparing both groups for values of $\mathrm{pH}, \mathrm{BE}, \mathrm{PCO}_{2}$, $\mathrm{PO}_{2}$, and lactate values. $\chi^{2}$ Testing was used for comparison of both groups with regard to univentricular or biventricular repair, ductus dependency, and mode of delivery.

\section{Results}

Between January 1, 1991, and June 30, 1998, 408 patients with congenital heart disease requiring operations within 31 days of life were admitted to the 3 participating institutions. Prenatal diagnosis in this group was established in $81(20 \%)$ patients at an average gestational age of 30.5 weeks, whereas 327 (80\%) patients only had postnatal diagnosis of their heart disease. Cesarean delivery was performed in $30.4 \%$ of the prenatal cases and $21.8 \%$ of the postnatal cases $(P=.31)$. The gestational age at delivery was $37.5 \pm$ 0.4 weeks (mean \pm SEM) in the group with prenatal diagnosis, whereas the patients with a postnatal diagnosis were delivered significantly later $(39.1 \pm 0.2$ weeks, $P<.001)$. Apgar scores were not different. Prostaglandin administration was required in $71 \%$ of both the prenatal and the postnatal patients. In the prenatal group prostaglandin was always started on the first day of life (SEM $=0$ ), and this differed significantly from the postnatal group, in which prostaglandin was started at $2.6 \pm 0.6$ days $(P<.001)$. No difference was found in the dosage or duration of prostaglandin administration (Table I). Patients with a prenatal diagnosis stayed in the hospital a mean time of 15.4 days, and those with a postnatal diagnosis stayed 19.9 days $(P=.55)$. The difference in outcome was not significant either. Of the prenatal group, $17 \%$ died within 31 days after birth compared with $19 \%$ in the postnatal group $(P=.87)$.

Laboratory results. Significant differences were found in the lowest arterial $\mathrm{pH}$ (prenatal vs postnatal, $7.31 \pm 0.01$ vs $7.28 \pm 0.01 ; P=.004)$ and the lowest preoperative $\mathrm{BE}$ (prenatal vs postnatal, $-4.90 \pm 0.45$ $\mathrm{mEq} / \mathrm{L}$ vs $-7.26 \pm 0.35 \mathrm{mEq} / \mathrm{L} ; P<.001$ ), with acidosis more common among the postnatally diagnosed group. Lactate was only measured in the patients seen in Utrecht because this is not a standard procedure in the 2 American centers in this study. The patients receiving prenatal and postnatal diagnoses had a highest lactate value of $3.14 \pm 0.57 \mathrm{mmol} / \mathrm{L}$ and $6.33 \pm 0.58 \mathrm{mmol} / \mathrm{L}$, respectively $(P<.001)$. No significant differences were found in highest arterial $\mathrm{PCO}_{2}$ and lowest $\mathrm{PO}_{2}$ (Table II).

Because very few blood gases were obtained 1 and 4 to 6 hours postpartum in the postnatal group, no significant differences were encountered for $\mathrm{pH}$ or $\mathrm{BE}$ at 
Table I. Gestational age at delivery, Apgar scores, and duration of alprostadil administration, alprostadil dose per minute, and total cumulative dosage of alprostadil

\begin{tabular}{|c|c|c|c|c|c|}
\hline & Prenatal diagnosis & $n$ & Mean & SEM & $\mathrm{P}$ value \\
\hline \multirow[t]{2}{*}{ Gestational age at delivery (wk) } & Yes & 44 & 37.45 & 0.40 & $<.001$ \\
\hline & No & 90 & 39.08 & 0.22 & \\
\hline \multirow[t]{2}{*}{ Apgar score, 1 min } & Yes & 43 & 7.60 & 0.22 & .93 \\
\hline & No & 95 & 7.58 & 0.18 & \\
\hline \multirow[t]{2}{*}{ Apgar score, $5 \mathrm{~min}$} & Yes & 43 & 8.56 & 0.13 & .55 \\
\hline & No & 95 & 8.66 & 0.10 & \\
\hline \multirow[t]{2}{*}{ Alprostadil administration (d) } & Yes & 30 & 4.30 & 0.40 & .44 \\
\hline & No & 55 & 4.89 & 0.52 & \\
\hline \multirow[t]{2}{*}{ Alprostadil dose $/ \min \left(\mu \mathrm{g} \cdot \mathrm{kg}^{-1} \cdot \min ^{-1}\right)$} & Yes & 36 & 0.044 & 0.009 & .16 \\
\hline & No & 66 & 0.060 & 0.007 & \\
\hline \multirow[t]{2}{*}{ Alprostadil total dose (mg/kg) } & Yes & 29 & 0.282 & 0.071 & .24 \\
\hline & No & 51 & 0.565 & 0.174 & \\
\hline
\end{tabular}

Patients with and without a prenatal diagnosis are compared.

these times. The only significant difference was for $\mathrm{PCO}_{2}$ after 1 hour (prenatal vs postnatal, $45.4 \pm 2.5$ vs $34.1 \pm 3.7 \mathrm{~mm} \mathrm{Hg} ; P=.015$; Table III).

The percentage of patients with markedly abnormal laboratory results was also compared. Lactate values over $7.5 \mathrm{mmol} / \mathrm{L}$ were found in $8.3 \%$ of the patients in the prenatal group compared with $24.5 \%$ in the postnatal group $(P=.29)$. The $\mathrm{pH}$ was lower than 7.20 in $8.8 \%$ of those having prenatal diagnosis and $20.7 \%$ of those having postnal diagnosis $(P=.02)$. BE lower than $-9.0 \mathrm{mEq} / \mathrm{L}$ was found in $28.3 \%$ in the postnatal group and in $11.8 \%$ in the prenatal group $(P=.005)$.

Ductus-dependent lesions versus non-ductusdependent lesions. In the same patient population, a difference was made between 2 groups, those with $(n=265)$ and those without $(n=109)$ a circulation depending on the persistence of a ductus arteriosus. When the same set of variables was compared for these groups, lowest $\mathrm{pH}$ (prenatal vs postnatal, $7.32 \pm 0.01$ vs $7.27 \pm 0.01 ; P=$ .005 ) and lowest BE (prenatal vs postnatal, $-5.15 \pm 0.54$ vs $-7.44 \pm 0.45 ; P=.002$ ) differed significantly in the ductus-dependent group, whereas only the lowest $\mathrm{BE}$ (prenatal vs postnatal, $-4.08 \pm 0.87$ vs $-6.83 \pm 0.58 ; P=$ .027) differed in the non-ductus-dependent group.

Single ventricular repair versus biventricular repair. Differences found between patients in this population requiring a single ventricular repair and those patients going for a 2-ventricle repair were the percentage of prenatal diagnosis made in these groups (univentricular vs biventricular, $33 \%$ vs $14 \% ; P<.001)$ and highest $\mathrm{Po}_{2}$ (univentricular vs biventricular, $37.5 \pm 1.8$ vs $45.0 \pm 2.5 ; P=.018)$.

Right-sided heart obstruction: Prenatal versus postnatal diagnosis. When comparing blood gases of prenatally and postnatally diagnosed infants with a right ventricular outflow tract obstruction, a significant difference was found in lowest arterial BE (prenatal vs postnatal, $-4.38 \pm 0.69$ vs $-6.64 \pm 0.59 ; P=.024$ ).

Left-sided heart obstruction: Prenatal versus postnatal diagnosis. In the group with a left ventricular outflow tract obstruction, both lowest BE (prenatal vs postnatal, $-5.03 \pm 0.78$ vs $-7.80 \pm 0.62 ; P=.007$ ) and lowest $\mathrm{pH}$ (prenatal vs postnatal, $7.32 \pm 0.02$ vs $7.27 \pm 0.02 ; P=.027$ ) differed significantly.

Prenatally diagnosed right-sided heart obstruction versus prenatally diagnosed left-sided heart obstruction. In comparing patients with a prenatal diagnosis of right and left ventricular outflow tract obstruction, significant differences were found in highest arterial $\mathrm{Po}_{2}$ (right vs left, $37.2 \pm 2.6$ vs $48.7 \pm 4.0$; $P=.038$ ) and highest arterial lactate (right vs left, 3.6 \pm 0.4 vs $1.3 \pm 0.3 ; P=.024)$.

\section{Discussion}

Prenatal diagnosis of congenital heart disease demands a high level of skill but one that is achievable during routine obstetric ultrasonography. ${ }^{13}$ The most convincing justification for such an effort would be to demonstrate that patients with a prenatal diagnosis have a better chance of a good outcome as a result of early initiation of therapy.

In $43 \%$ of the patients the diagnosis was made before 24 weeks' gestation, an age at which termination of pregnancy is still a legal option, but the parents opted for continuation of the pregnancy with a planned delivery. Although the number of cesarean deliveries was not significantly higher, the gestational age at delivery was significantly lower in infants with a prenatal diagnosis, probably because of the planned induction of the delivery to ensure optimal postnatal care. 
Volume 121, Number 4

Table II. Arterial blood gases in the preoperative period

\begin{tabular}{|c|c|c|c|c|c|}
\hline & Prenatal diagnosis & $n$ & Mean & SEM & $\mathrm{P}$ value \\
\hline \multirow[t]{2}{*}{ Lowest $\mathrm{pH}$} & Yes & 67 & 7.31 & 0.01 & .004 \\
\hline & No & 293 & 7.28 & 0.01 & \\
\hline \multirow[t]{2}{*}{ Lowest BE (mEq/L) } & Yes & 67 & -4.90 & 0.45 & $<.001$ \\
\hline & No & 291 & -7.26 & 0.35 & \\
\hline \multirow[t]{2}{*}{ Highest $\mathrm{PCO}_{2}(\mathrm{~mm} \mathrm{Hg})$} & Yes & 41 & 45.14 & 2.03 & .244 \\
\hline & No & 88 & 48.72 & 1.86 & \\
\hline \multirow{2}{*}{ Lowest $\mathrm{Po}_{2}(\mathrm{~mm} \mathrm{Hg})$} & Yes & 41 & 42.90 & 2.46 & .956 \\
\hline & No & 83 & 42.68 & 2.49 & \\
\hline \multirow[t]{2}{*}{ Highest lactate $(\mathrm{mmol} / \mathrm{L})$} & Yes & 11 & 3.14 & 0.57 & $<.001$ \\
\hline & No & 99 & 6.33 & 0.58 & \\
\hline
\end{tabular}

Patients with and without prenatal diagnosis are compared.

No difference was found in Apgar scores between both groups, which could be expected because cardiac status in the delivery room rarely differed between the 2 groups as a result of ductal patency and the absence of significant left-to-right shunting before the postnatal drop in pulmonary vascular resistance.

Total cumulative dosage of alprostadil (prostaglandin $\mathrm{E}_{1}$ ) was no different, and therefore no difference in side effects is to be expected between the 2 patient groups. ${ }^{14-17}$ Alprostadil administration was, if required, always started on the first day of life in the prenatal group, whereas administration was started after 2.6 days in the postnatal group. This is likely due to the fact that decreased ductal flow among the infants with a postnatal diagnosis resulted in the symptoms leading to initial diagnosis.

Although hypoxemia or ischemia may result in metabolic acidosis, highest $\mathrm{PCO}_{2}$ and lowest $\mathrm{Po}_{2}$ values were no different between the 2 patient groups, suggesting that the predominant cause of acidosis is hypoperfusion rather than hypoxemia with early alprostadil infusion affecting systemic perfusion.

In our study prenatal diagnosis did lead to a significant prevention of deterioration of the acid-base equilibrium. A positive effect of prenatal detection on surgical outcome has been suggested in previous reports, ${ }^{8-12}$ but we could not affirm such a direct effect. Eapen and colleagues ${ }^{12}$ analyzed a specific population with left ventricular outflow tract obstruction and found a significant difference in BE in first blood gases in favor of the prenatally diagnosed group. Our study covers the entire spectrum of congenital heart disease and reports on representative information about the actual acidosis obtained at fixed time intervals after birth or by analyzing worst blood gases and demonstrates a significant difference in the severity of acidosis in favor of the group of patients with a prenatal diagnosis of congenital heart disease. This outcome suggests that immediate management of heart disease facilitated by the prenatal diagnosis of the disease diminishes acidosis and allows immediate stabilization of the acid-base equilibrium. Comparison of markedly abnormal laboratory values shows that a prenatal diagnosis helps in prevention of extreme acidosis.

The importance of avoidance of severe metabolic acidosis to prevent brain damage has been suggested in previous reports. Enhanced acidosis may exaggerate ischemic, glial, and vascular cell damage because it accelerates delocalization of protein-bound iron, with an ensuing free-radical damage to membrane lipids and proteins. ${ }^{18-21}$ Prevention of metabolic acidosis might, in addition, lead to better surgical outcomes. ${ }^{22-25}$ Postoperative lactate levels are higher for nonsurvivors and may be a useful predictor of mortality in children less than 1 year of age. ${ }^{22-25}$

The comparison of prenatally and postnatally diagnosed patients with ductus-dependent lesions showed significant differences for lowest $\mathrm{BE}$ and lowest $\mathrm{pH}$, and in patients with non-ductus-dependent lesions, only lowest BE differed significantly in favor of the prenatal group. This implicates that especially the early initiation of alprostadil administration in the ductusdependent group prevents acidosis, whereas the difference in the non-ductus-dependent group, although less significant, suggests that early initiation of medical care, other than prostaglandin therapy, is another positive factor of prenatal diagnosis. In most cases, however, prostaglandin administration can be delayed for 2 to 3 hours after birth because the ductus arteriosus will normally stay widely patent in the first several hours.

Comparing patients with a future possibility of biventricular repair to those with an anticipated single ventricular repair, the only statement to be made is the obvious higher percentage of prenatal diagno- 
Table III. Arterial blood gases 1 and 4 to 6 hours after birth

\begin{tabular}{|c|c|c|c|c|c|}
\hline & Prenatal diagnosis & $n$ & Mean & SEM & $\mathrm{P}$ value \\
\hline \multirow[t]{2}{*}{$\mathrm{pH}, 1 \mathrm{~h}$} & Yes & 14 & 7.31 & 0.02 & .287 \\
\hline & No & 10 & 7.35 & 0.03 & \\
\hline \multirow[t]{2}{*}{$\mathrm{BE}, 1 \mathrm{~h}(\mathrm{mEq} / \mathrm{L})$} & Yes & 14 & -4.32 & 1.12 & .461 \\
\hline & No & 9 & -5.78 & 1.68 & \\
\hline \multirow{2}{*}{$\mathrm{PCO}_{2}, 1 \mathrm{~h}(\mathrm{~mm} \mathrm{Hg})$} & Yes & 14 & 45.43 & 2.54 & .015 \\
\hline & No & 10 & 34.10 & 3.67 & \\
\hline \multirow[t]{2}{*}{$\mathrm{Po}_{2}, 1 \mathrm{~h}(\mathrm{~mm} \mathrm{Hg})$} & Yes & 14 & 43.50 & 4.39 & .744 \\
\hline & No & 10 & 45.90 & 6.01 & \\
\hline \multirow[t]{2}{*}{$\mathrm{pH}, 4-6 \mathrm{~h}$} & Yes & 18 & 7.37 & 0.02 & .216 \\
\hline & No & 11 & 7.31 & 0.05 & \\
\hline \multirow[t]{2}{*}{$\mathrm{BE}, 4-6 \mathrm{~h}(\mathrm{mEq} / \mathrm{L})$} & Yes & 18 & -0.82 & 0.58 & .051 \\
\hline & No & 12 & -4.81 & 1.77 & \\
\hline \multirow{2}{*}{$\mathrm{PCO}_{2}, 4-6 \mathrm{~h}(\mathrm{~mm} \mathrm{Hg})$} & Yes & 18 & 43.06 & 1.95 & .063 \\
\hline & No & 12 & 37.08 & 2.40 & \\
\hline \multirow{2}{*}{$\mathrm{Po}_{2}, 4-6 \mathrm{~h}(\mathrm{~mm} \mathrm{Hg})$} & Yes & 18 & 44.39 & 2.95 & .840 \\
\hline & No & 12 & 43.25 & 5.23 & \\
\hline
\end{tabular}

Patients with and without prenatal diagnosis are compared.

sis in the last group because of the presence of a distinctly abnormal 4-chamber view, which facilitates early diagnosis.

The separate analysis of patients with and without prenatal diagnosis of right-sided heart obstruction, leftsided heart obstruction, or no obstruction reveals a significant difference in lowest $\mathrm{BE}$ in favor of the prenatal group for the right-sided heart obstruction, lowest $\mathrm{BE}$ and $\mathrm{pH}$ for left-sided heart obstruction, and no significant difference for the group without obstruction. This indicates that also in the group with right-sided heart obstruction, prenatal diagnosis has a positive effect on prevention of metabolic acidosis.

The power of the numbers is small, especially when groups of patients are separated out, which makes significance hard to reach in subgroups. This includes the important group of transposition of the great arteries, where Bonnet and colleagues ${ }^{8}$ showed that prenatal detection reduced neonatal mortality. Our data did not allow such a conclusion, although the surgical outcomes of all patients have been investigated. The number of influencing parameters, such as different surgeons, different institutions, and different protocols prevented a clean analysis.

In conclusion, prenatal diagnosis diminishes the development of metabolic acidosis in the newborn patient with congenital heart disease without an apparent effect on immediate surgical outcome. Although in this study the differences are significant but small, they indicate a first step toward a better-controlled preoperative approach, which will allow an optimization of the preoperative condition of the patient with severe congenital heart disease. We postulate that this improvement in preoperative condition may lead to improved long-term outcome and prevention of cerebral damage among this fragile group of patients.

Received for publication April 3, 2000; revisions requested May 30, 2000; revisions received Oct 11, 2000; accepted for publication Oct 20, 2000.

Address for reprints: Ger B. W. E. Bennink, Department of Thoracic Surgery, University Medical Center (UMC), KG 01.3190/PO Box 85090, 3508 AB Utrecht, The Netherlands.

\section{REFERENCES}

1. Centers for Disease Control. Contribution of birth defects to infants' mortality-United States 1986. MMWR Morb Mortal Wkly Rep 1989;38:633-5.

2. Kern JH, Hinton VJ, Nereo NE, Hayes CJ, Gersony WM. Early developmental outcome after the Norwood procedure for hypoplastic left heart syndrome. Pediatrics 1998;102:1148-52.

3. Kirkham FJ. Recognition and prevention of neurological complications in pediatric cardiac surgery. Pediatr Cardiol 1998;19:331-45.

4. Du Plessis AJ. Neurologic complications of cardiac disease in the newborn. Clin Perinatol 1997;24:807-26.

5. Soongswang J, Adatia I, Newman C, Smallhorn JF, Williams WG, Freedom RM. Mortality in potential arterial switch candidates with transposition of the great arteries. J Am Coll Cardiol 1998;32:753-7.

6. Bove EL, Bull C, Stark J, de Leval M, Macartney FJ, Taylor JFN. Congenital heart disease in the neonate: results of surgical treatment. Arch Dis Child 1983;58:137-41.

7. Olly PM, Coceani F, Bodach E. E-type prostaglandins. Circulation 1975;53:728-31.

8. Bonnet D, Coltri A, Butera G, Fermont L, Le Bidois J, Kachaner $\mathrm{J}$, et al. Detection of transposition of the great arteries in fetuses reduces neonatal morbidity and mortality. Circulation 1999;99:916-8.

9. Copel JA, Tan ASA, Kleinman CS. Does a prenatal diagnosis of congenital heart disease alter short-term outcome? Ultrasound Obstet Gynecol 1997;10:237-41. 
10. Chang AC, Huhta JC, Yoon GY, Wood DC, Tulzer G, Cohen A, et al. Diagnosis, transport, and outcome in fetuses with left ventricular outflow tract obstruction. J Thorac Cardiovasc Surg 1991;102:841-8.

11. Montana E, Khoury MJ, Cragan JD, Sharma S, Dhar P, Fyfe D. Trends and outcomes after prenatal diagnosis of congenital cardiac malformations by fetal echocardiography in a well defined birth population, Atlanta, Georgia, 1990-1994. J Am Coll Cardiol 1996;28:1805-9.

12. Eapen RS, Rowland DG, Franklin WH. Effect of prenatal diagnosis of critical left heart obstruction on perinatal morbidity and mortality. Am J Perinatol 1998;15:237-42.

13. Yagel S, Weissman A, Rotstein Z, Manor M, Hegesh J, Anteby E, et al. Congenital heart defects: natural course and in utero development. Circulation 1997;96:550-5.

14. Hallidie-Smith KA. Prostaglandin $E_{1}$ in suspected ductus dependent cardiac malformation. Arch Dis Child 1984;59:1020-6.

15. Höst A, Halken S, Kamper J, Lillquist K. Prostaglandin E1 treatment in ductus dependent congenital cardiac malformation. Dan Med Bull 1988;35:81-4.

16. Kramer HH, Sommer M, Rammos S, Krogmann O. Evaluation of low dose prostaglandin $\mathrm{E}_{1}$ treatment for ductus dependent congenital heart disease. Eur J Pediatr 1995;154:700-7.

17. Teixeira OHP, Carpenter B, MacMurray SB, Vlad P. Long-term prostaglandin $\mathrm{E}_{1}$ therapy in congenital heart defects. J Am Coll Cardiol 1984;3:838-43.
18. Siesjö BK. Mechanisms of ischemic brain damage. Crit Care Med 1988;16:954-63.

19. Myers RE. Lactic acid and accumulation as cause of brain edema and cerebral necrosis resulting from oxygen deprivation. In Korobkin R, Guilleminault G, editors. Advances in perinatal neurology. New York: Spectrum; 1979. p. 85.

20. Siesjo BK, Katsura KI, Kristian T, Li PA, Siesjo P. Molecular mechanisms of acidosis-mediated damage. Acta Neurochir Suppl 1996;66:8-14

21. Siesjo BK, Ekholm A, Katsura K, Theander S. Acid-base changes during complete brain ischemia. Stroke 1990;21(Suppl III):III-194-9.

22. Siegel LB, Dalton HJ, Hertzog JH, Hopkins RA, Hannan RL, Hauser GJ. Initial postoperative serum lactate levels predict survival in children after open heart surgery. Intensive Care Med 1996;22:1418-23.

23. Cheifetz IM, Kern FH, Schulman SR, Greeley WJ, Ungerleider RM, Meliones JN. Serum lactates correlate with mortality after operations for complex congenital heart disease. Ann Thorac Surg 1997;64:735-8.

24. Hatherill M, Sajjanhar T, Tibby SM,Champion MP, Anderson D, Marsh MJ, et al. Serum lactate as a predictor of mortality after pediatric cardiac surgery. Arch Dis Child 1997;77:235-8.

25. Forbess J, Cook N, Roth S, Serraf A, Mayer JJ, Jonas R. Tenyear institutional experience with palliative surgery for hypoplastic left heart syndrome-risk factors related to stage I mortality. Circulation 1995;92(Suppl):II-262-6. 